\title{
The impact of single-nucleotide polymorphisms on liver stiffness and controlled attenuation parameter in patients treated with direct-acting antiviral drugs for hepatitis $\mathbf{C}$ infection
}

\author{
KOSUKE MATSUMOTO, HISAMITSU MIYAAKI, MASANORI FUKUSHIMA, RYU SASAKI, \\ MASAFUMI HARAGUCHI, SATOSHI MIUMA and KAZUHIKO NAKAO
}

Department of Gastroenterology and Hepatology, Nagasaki University Graduate School of Biomedical Sciences, Nagasaki 852-8501, Japan

Received August 21, 2021; Accepted November 18, 2021

DOI: $10.3892 /$ br.2021.1492

\begin{abstract}
Single-nucleotide polymorphisms (SNPs) of patatin-like phospholipase domain-containing 3 (PNPLA3), tolloid-like protein 1 (TLL1) and interleukin-28 (IL28) have been identified as susceptibility factors for liver steatosis, inflammation and fibrosis in patients with hepatitis $\mathrm{C}$ virus (HCV) infection. Here, whether these polymorphisms affected predispositions to changes in liver stiffness (LS) and controlled attenuation parameter (CAP) following direct-acting antiviral (DAA) therapy was assessed. The changes in LS and steatosis in $77 \mathrm{HCV}$-infected patients receiving DAA therapy were compared with PNPLA3, TLL1 and IL28 genotypes, using CAP, FibroScan and Virtual Touch tissue quantification (VTTQ) before treatment and 12 weeks after the end of the treatment. VTTQ results showed that LS significantly decreased in PNPLA3 CC $(\mathrm{P}=0.035)$, TLL1 AA $(\mathrm{P}=0.011)$ and $I L 28 B$ TT $(\mathrm{P}=0.005)$ genotypes; no significant differences were observed in PNPLA3 CG/GG, TLL1 AT/TT and $I L 28 B$ TG/GG. FibroScan results showed that LS significantly decreased in TLLI AA $(\mathrm{P}=0.028)$ and $I L 28 B$ TT $(\mathrm{P}=0.032)$, with no significant difference in PNPLA3 CC. No significant differences were observed in PNPLA3 CG/GG, TLL1 AT/TT and $I L 28 B$ TG/GG groups. CAP was significantly increased in PNPLA3 CG/GG $(\mathrm{P}=0.039$ and $\mathrm{P}<0.05)$ and IL28B TT $(\mathrm{P}=0.014)$; no significant difference was observed in PNPLA3 $\mathrm{CC}$ and all genotypes of $T L L 1$ and $I L 28 B$ TG/GG. Therefore, these results indicated that SNPs could predict changes in LS and steatosis after DAA therapy.
\end{abstract}

Correspondence to: Dr Hisamitsu Miyaaki, Department of Gastroenterology and Hepatology, Nagasaki University Graduate School of Biomedical Sciences, 1-7-1 Sakamoto, Nagasaki 852-8501, Japan

E-mail: miyaaki-hi@umin.ac.jp

Key words: single nucleotide polymorphisms, direct-acting antiviral therapy, hepatitis $\mathrm{C}$, liver stiffness, steatosis, controlled attenuation parameter

\section{Introduction}

Research on genome-wide association analyses and the association of single-nucleotide polymorphisms (SNPs) with various diseases have seen great advances (1). The association between the pathophysiology of chronic liver disease and SNPs has also been reported. Patatin-like phospholipase domain-containing 3 (PNPLA3) rs738409 (2-4), tolloid-like protein 1 (TLL1) $r s 17047200$ (5-7) and interleukin-28B (IL28b) rs809917 (8-14) are associated with liver fibrosis, inflammation and steatosis in hepatitis $\mathrm{C}$ virus (HCV)-infected patients.

Liver biopsy is considered the gold standard for evaluating liver histology, including steatosis, inflammation and fibrosis; however, it is an invasive procedure that can cause various complications such as pain, fever, and bleeding (15). To address this limitation, FibroScan and Virtual Touch tissue quantification (VTTQ) were developed as modalities for the non-invasive assessment of liver fibrosis $(16,17)$. In addition, FibroScan includes software for assessing hepatic steatosis using controlled attenuation parameter (CAP) (16). These modalities can be used to repeatedly evaluate liver steatosis, inflammation and fibrosis.

Hepatitis $\mathrm{C}$ is a disease that causes cirrhosis and hepatocellular carcinoma. It is estimated that 177.5 million individuals worldwide are infected with $\mathrm{HCV}$, which is $2.5 \%$ of the world's population (17). HCV infection poses a significant risk of cirrhosis and liver cancer. Originally, interferon-based treatment was used as the treatment for $\mathrm{HCV}$, but the elimination rate of HCV was low, and adverse events frequently appeared (18). Direct-acting antivirals (DAAs) have been used as a treatment for $\mathrm{HCV}$, and a high treatment success rate has been reported (19). Ogasawara et al (20) reported the influence of DAA therapy on liver stiffness (LS) and CAP, finding that the treatment of $\mathrm{HCV}$ with DAA decreases LS and increases CAP after treatment. Therefore, in this study, the impact of three SNPs (PNPLA3, TLL1 and IL28B) on changes in CAP and LS following DAA therapy were examined.

\section{Materials and methods}

Patients. A total of 78 seven patients (39 females and 38 males; median age, 68 years; age range, $33-88$ years) 
who received DAA therapy for chronic HCV infection at Nagasaki University Hospital (Nagasaki, Japan) and were subsequently confirmed as HCV-negative 12 weeks after the end of treatment [sustained virologic response (SVR12)] between September 2014 and December 2017 were enrolled in the study.

The patients' profiles and the results of laboratory data at the start of DAA therapy are summarized in Table I. Written informed consent was obtained from all patients, and the study protocol conformed to the ethical guidelines of the 1975 Declaration of Helsinki (21). This study was approved by the Ethics Committee of Nagasaki University (approval no. 15012688-3).

Measurement of LS and CAP. LS was measured twice, at the baseline (before DAA therapy) and 12 weeks after the end of the treatment (sustained virologic response, 12 weeks after the end of direct-acting antiviral treatment; SVR12). LS was measured by VTTQ [LS (VTTQ)] using an ACUSON S2000 (Siemens AG) and by transient elastography with the M-probe of FibroScan 502 Touch (Echosens) [LS (FibroScan)]. The CAP was also measured using FibroScan. The patient was examined in a supine position with their right arm raised. The tip of the probe was placed on the skin of the patient between the ribs and the right lobe of the liver. For VTTQ measurement, the region of interest was located 2-4 $\mathrm{cm}$ under the capsule in the right lobe to avoid major blood vessels. Measurements were taken five times and the median was used for analysis. The LS results after VTTQ are presented as m/s (22). For FibroScan measurement, the probe was placed on the skin between the ribs and aimed at a location similar to that used for VTTQ. Measurements were taken 10 times, and the median was used for analysis. The LS results after FibroScan are presented as $\mathrm{kPa}$, and $\mathrm{CAP}$ results are presented as $\mathrm{dB} / \mathrm{m}(23,24)$.

SNP genotyping. Genomic DNA was extracted from mononuclear cells in peripheral blood samples of each patient using a FlexiGene DNA kit (Qiagen $\mathrm{GmbH}$ ). The SNPs in $P N P L A 3, T L L 1$ and $I L 28 B$ were genotyped in each sample using TaqMan SNP genotyping assays kit (Thermo Fisher Scientific, Inc.) containing two allele-specific TaqMan MGB probes labeled with different fluorochromes and a PCR primer pair according to the manufacturer's protocol. The following primers were used: PNPLA3 rs738409, AGGCCTTGGTAT GTTCCTGCTTCAT[C/G]CCCTTCTACAGTGGCCTTATC CCTC (cat. no. 4351379); TLL1 rs17047200, TTTTGCCCA CTTATGTCCATTTCAC[A/T]GTTCATTGACATCTATTT CTGAAGG (cat. no. 4351379); IL28B rs8099917, TTTTGT TTTCCTTTCTGTGAGCAAT[G/T]TCACCCAAATTGGAA CCATGCTGTA (cat. no. 4351379). As an example, the data for PNPLA3 are shown in Fig. S1. The protocol was the same as that described in a previous study (25).

Statistical analysis. Data are presented as the median (inter-quartile range). Pre- and post-treatment data were analyzed by a Wilcoxon signed-rank test. $\mathrm{P}<0.05$ was considered to indicate a statistically significant difference. Statistical analysis was performed using the StatFlex software (version 6.0; Artech).

\section{Results}

Whole group analysis. Fig. 1 shows the changes in LS (VTTQ), LS (FibroScan) and CAP from before treatment and at SVR12. In the whole group, the median LS (VTTQ) values decreased significantly $(\mathrm{P}=0.006)$ from 1.33 to $1.21 \mathrm{~m} / \mathrm{s}$ from the start of the treatment to SVR12. The median LS (FibroScan) values decreased significantly $(\mathrm{P}=0.017)$ from 6.10 to $5.80 \mathrm{kPa}$, and the median CAP values increased significantly $(\mathrm{P}=0.048)$ from 210 to $226 \mathrm{~dB} / \mathrm{m}$.

The PNPLA3 genotype frequencies were as follows: CC, 32 patients (42\%); CG, 30 patients (39\%); and GG, 15 patients (19\%). The TLL1 genotype frequencies were as follows: AA, 57 patients (74\%); AT, 20 patients (26\%); and TT, no patients $(0 \%)$. The $I L 28 B$ genotype frequencies were as follows: TT, 57 patients (74\%); TG, 18 patients (23\%); and GG, two patients (3\%). We divided PNPLA3 into CC and CG/GG groups, TLL1 into AA and AT(/TT) groups, and $I L 28 B$ into TT and TG/GG groups.

Changes in $L S$ (VTTQ). Fig. 2 shows the changes in the LS (VTTQ) for each SNP. In PNPLA3, the median values of CC decreased significantly ( $\mathrm{P}=0.035)$ from 1.39 to $1.19 \mathrm{~m} / \mathrm{s}$. The median values of $\mathrm{CG} / \mathrm{GG}$ did not change significantly from 1.31 to $1.25 \mathrm{~m} / \mathrm{s}$. Even after dividing CG/GG genotypes into $C G$ and $G G$, no significant difference was found between CG and GG. In TLL1, the median values of AA decreased significantly $(\mathrm{P}=0.011)$ from 1.31 to $1.19 \mathrm{~m} / \mathrm{s}$. The median values of AT did not change significantly from 1.43 to $1.26 \mathrm{~m} / \mathrm{s}$. In $I L 28 B$, the median values of TT decreased significantly $(\mathrm{P}=0.005)$ from 1.36 to $1.19 \mathrm{~m} / \mathrm{s}$. The median values of TG/GG did not change significantly from 1.31 to $1.36 \mathrm{~m} / \mathrm{s}$.

Changes in LS (FibroScan). Fig. 3 shows changes in LS (FibroScan) for each SNP. In PNPLA3, the median values of CC decreased from $6.15 \mathrm{kPa}$ before treatment to $5.75 \mathrm{kPa}$ at SVR12, but the decrease was not significant. The median values of $\mathrm{CG} / \mathrm{GG}$ did not change significantly from 6.10 to $5.80 \mathrm{kPa}$. Even after dividing CG/GG into CG and GG, no significant difference was found between CG and GG. In $T L L 1$, the median values of AA decreased significantly $(\mathrm{P}=0.028)$ from 6.10 to $5.75 \mathrm{kPa}$. The median values of AT did not change significantly from 6.60 to $5.10 \mathrm{kPa}$. In $I L 28 B$, the median values of TT decreased significantly $(\mathrm{P}=0.032)$ from 6.10 to $5.50 \mathrm{kPa}$. The median values of TG/GG did not change significantly from 6.70 to $7.40 \mathrm{kPa}$.

Changes in CAP. Fig. 4 shows the changes in CAP for each SNP. In PNPLA3, the median values of CC did not change significantly from 217 to $209 \mathrm{~dB} / \mathrm{m}$. The median values of $\mathrm{CG} / \mathrm{GG}$ increased significantly $(\mathrm{P}=0.004)$ from 204 to $233 \mathrm{~dB} / \mathrm{m}$. After dividing CG/GG into CG and GG, both CG $(\mathrm{P}=0.039)$ and $\mathrm{GG}(\mathrm{P}<0.05)$ increased significantly. In TLL1, the median values of AA did not change significantly from 207 to $226 \mathrm{~dB} / \mathrm{m}$. The median values of AT did not change significantly from 215 to $225 \mathrm{~dB} / \mathrm{m}$. In $I L 28 B$, the median values of TT increased significantly ( $\mathrm{P}=0.014)$ from 213 to $226 \mathrm{~dB} / \mathrm{m}$. The median values of TG/GG did not change significantly from 206 to $218 \mathrm{~dB} / \mathrm{m}$. 
Table I. Baseline characteristics of the patients $(n=77)$.

\begin{tabular}{|c|c|}
\hline Parameter & Value \\
\hline Age, years (range) & $68(33-88)$ \\
\hline \multicolumn{2}{|l|}{ Sex, n } \\
\hline Males & 38 \\
\hline Females & 39 \\
\hline Chronic hepatitis, $\mathrm{n}$ & 53 \\
\hline Liver cirrhosis, $\mathrm{n}$ & 24 \\
\hline Total bilirubin, $\mathrm{mg} / \mathrm{dl}^{\mathrm{a}}$ & $0.9(0.3-2.5)$ \\
\hline Albumin, $\mathrm{g} / \mathrm{dl}^{\mathrm{a}}$ & $3.9(2.5-4.9)$ \\
\hline Low density lipoprotein cholesterol, mg/dl ${ }^{\mathrm{a}}$ & $88.8(31-158)$ \\
\hline Platelet count, $10^{4} / \mu 1^{\mathrm{a}}$ & $17.8(3.9-47.0)$ \\
\hline Aspartate aminotransferase, $\mathrm{IU} / 1^{\mathrm{a}}$ & $49.2(10-188)$ \\
\hline Alanine aminotransferase, $\mathrm{IU} / \mathrm{l}^{\mathrm{a}}$ & $40.0(26.5-56.3)$ \\
\hline Total cholesterol, mg/dl ${ }^{\mathrm{a}}$ & $166.1(112-241)$ \\
\hline Mac-2 binding protein glycosylation isomer ${ }^{\mathrm{a}}$ & $2.39(0.37-14.57)$ \\
\hline Body mass index, $\mathrm{kg} / \mathrm{m}^{2 \mathrm{a}}$ & $22.5(15.6-29.0)$ \\
\hline Liver stiffness measured using Virtual Touch Tissue Quantification, m/s ${ }^{\mathrm{a}}$ & $1.57(0.75-3.77)$ \\
\hline Liver stiffness measured using FibroScan, $\mathrm{kPa}^{\mathrm{a}}$ & $6.30(4.40-11.63)$ \\
\hline Controlled attenuation parameter, $\mathrm{dB} / \mathrm{m}^{\mathrm{a}}$ & $213.7(100-373)$ \\
\hline Direct acting antiviral agent, $\mathrm{n}$ & $14 / 7 / 32 / 9 / 13 / 2$ \\
\hline Daclatasvir/asunaprevir & 14 \\
\hline Sofosbuvir + ribavirin & 7 \\
\hline Sofosbuvir/ledipasvir & 32 \\
\hline Ombitasvir/paritaprevir/ritonavir & 9 \\
\hline Elbasvir/grazoprevir & 13 \\
\hline Glecaprevir/pibrentasvir & 2 \\
\hline \multicolumn{2}{|l|}{ PNPLA3 (rs738409) genotype, $\mathrm{n}$} \\
\hline $\mathrm{CC}$ & 32 \\
\hline CG & 30 \\
\hline GG & 15 \\
\hline \multicolumn{2}{|l|}{ TLL1 (rs17047200) genotype, $\mathrm{n}$} \\
\hline AA & 57 \\
\hline AT & 20 \\
\hline TT & 0 \\
\hline \multicolumn{2}{|l|}{ IL28B (rs8099917) genotype, n } \\
\hline TT & 57 \\
\hline TG & 18 \\
\hline GG & 2 \\
\hline
\end{tabular}

${ }^{\mathrm{a}}$ Median (range).

\section{Discussion}

In this study, the impact of SNPs on changes in LS and CAP after DAA therapy in patients with HCV infection were determined. LS was evaluated using VTTQ and FibroScan, and CAP was evaluated using FibroScan. LS (VTTQ) and LS (FibroScan) significantly decreased, and CAP significantly increased at SVR12 in all cases. These results are consistent with those of a previous study (20). LS reflects liver fibrosis staging and liver inflammation; therefore, a decrease in LS indicates an improvement in fibrosis and inflammation.
PNPLA3 rs738409 is considered a risk factor for liver steatosis, fibrosis progression, and the development of hepatocellular carcinoma in patients with non-alcoholic fatty liver disease (26,27). Moreover, a previous study reported that PNPLA3 is a significant risk factor for steatosis, inflammation and fibrosis in patients with hepatitis C (2-4). Furthermore, PNPLA3 is reportedly involved in lipase activity, and a $\mathrm{C}$ to $\mathrm{G}$ substitution causes an amino acid substitution from isoleucine to methionine at position 148 of the coding sequence (I148M), with the resulting loss of function possibly involved in hepatic steatosis. It is also possible that I148M affects the activation of 
A

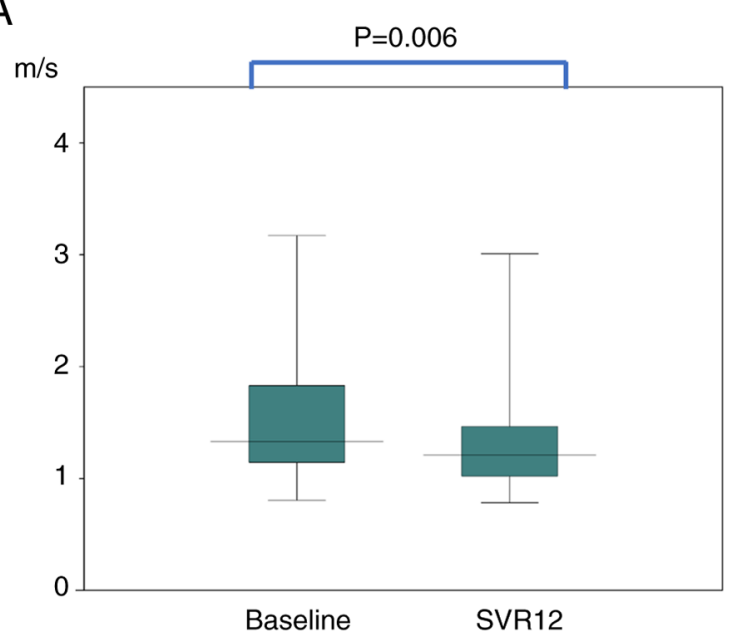

C

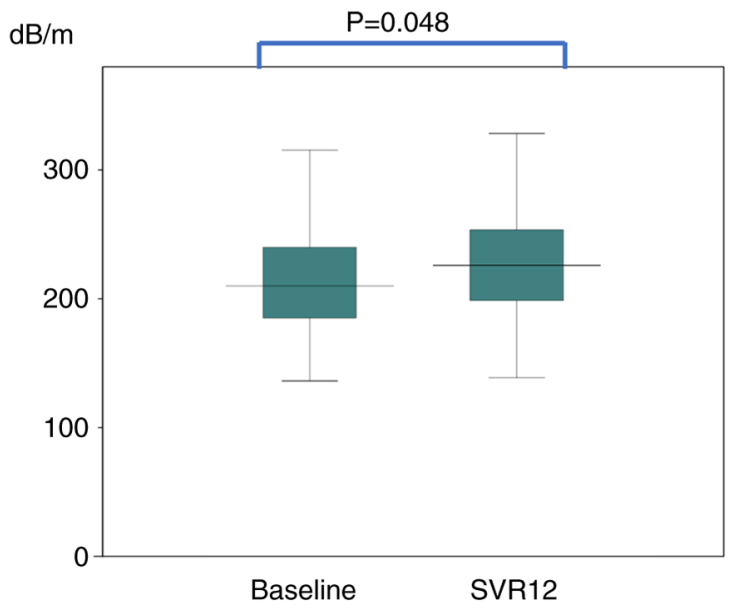

B

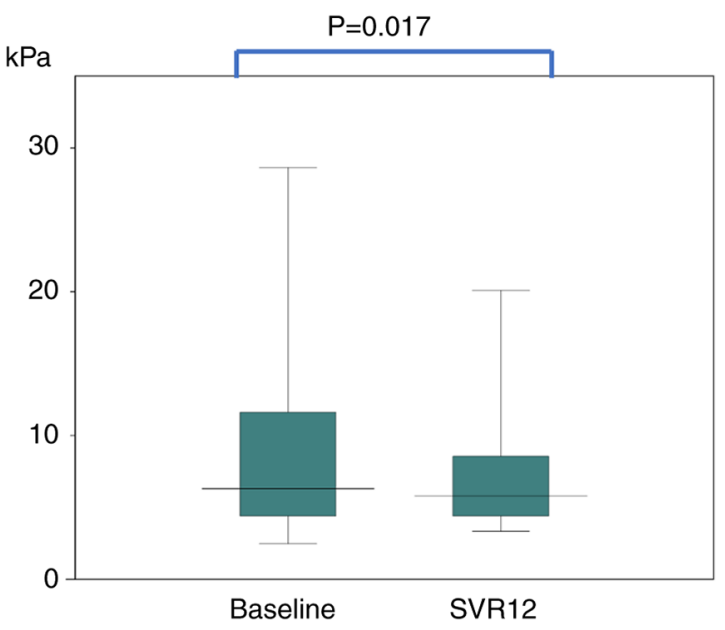

\begin{tabular}{l|l} 
(A) LS (VTTQ) & (B) LS (Fibroscan)
\end{tabular}

Figure 1. Change in LS and CAP before DAA treatment and at SVR12. Changes in (A) LS (VTTQ), (B) LS (FibroScan) and (C) CAP before treatment and at SVR12 for all patients. The median LS (VTTQ) values decreased significantly ( $\mathrm{P}=0.006)$ from $1.33 \mathrm{~m} / \mathrm{s}$ before treatment to $1.21 \mathrm{~m} / \mathrm{s}$ at $\mathrm{SVR} 12$. The median LS (FibroScan) values decreased significantly ( $\mathrm{P}=0.017$ ) from 6.10 to $5.80 \mathrm{kPa}$. The median $\mathrm{CAP}$ values increased significantly $(\mathrm{P}=0.048)$ from 210 to $226 \mathrm{~dB} / \mathrm{m}$. LS, liver stiffness; VTTQ, virtual touch tissue quantification; HCV, hepatitis C virus; DAA, direct-acting antiviral therapy; CAP, controlled attenuation parameter; SVR12, sustained virologic response, 12 weeks after the end of direct-acting antiviral treatment.

hepatic stellate cells related to fibrosis; however, the associated mechanism has not yet been elucidated (2-4). Previous studies suggested that TLL1 rs17047200 may contribute to hepatocarcinogenesis through the progression of liver fibrosis and that the AT/TT genotype is a risk factor for the development of HCC after SVR (5-7). Furthermore, TLL1 may be involved in the development of hepatic fibrosis through extracellular matrix production and TGF- $\beta$ signal activation (5-7). Another report indicated that SNPs located close to $I L 28 B$ significantly influenced the therapeutic outcome of combination therapy involving pegylated IFN and ribavirin in $\mathrm{HCV}$-infected patients (28). Additionally, liver fibrosis is reportedly exacerbated by the minor $(14)$ and major alleles $(8,13)$ of $I L 28 B$ $r s 80991$, with a previous report suggesting that changes in the $I L 28 B$ allele alter the expression levels of IFN-stimulating genes, including some inflammatory cytokines, and may be involved in fibrosis. Moreover, increased IFN expression reportedly suppresses lipoprotein lipase activity and reduces very-low-density lipoprotein levels through low-density lipoprotein conversion, which may be involved in hepatic steatosis $(8,13)$. These findings suggest the involvement of these SNPs in steatosis, inflammation and fibrosis in patients with chronic hepatitis, and the observed changes in LS and CAP in this study are consistent with previous findings.

Previous studies showed that HCV eradication by IFN and DAA therapy led to downstaging of fibrosis and reduced HCC incidence, particularly in patients who achieved SVR (29-31). However, HCC development can occur even in patients with SVR, and the major risk factors include older age, alcohol intake, pathological factors and diabetes (32-35). Motoyama et al (36) reported that stagnation of fibrosis regression is associated with a high risk of HCC development after SVR. Additionally, liver steatosis is reportedly a risk factor for HCC development after SVR (37). Given these findings, elevations in LS and CAP following DAA may represent a risk factor for HCC development. Therefore, patients found to possess these risk alleles need careful follow-ups with their doctors considering the risk of HCC.

In the present study, median LS (VTTQ) and LS (FibroScan) increased after treatment in IL28B TG/GG 

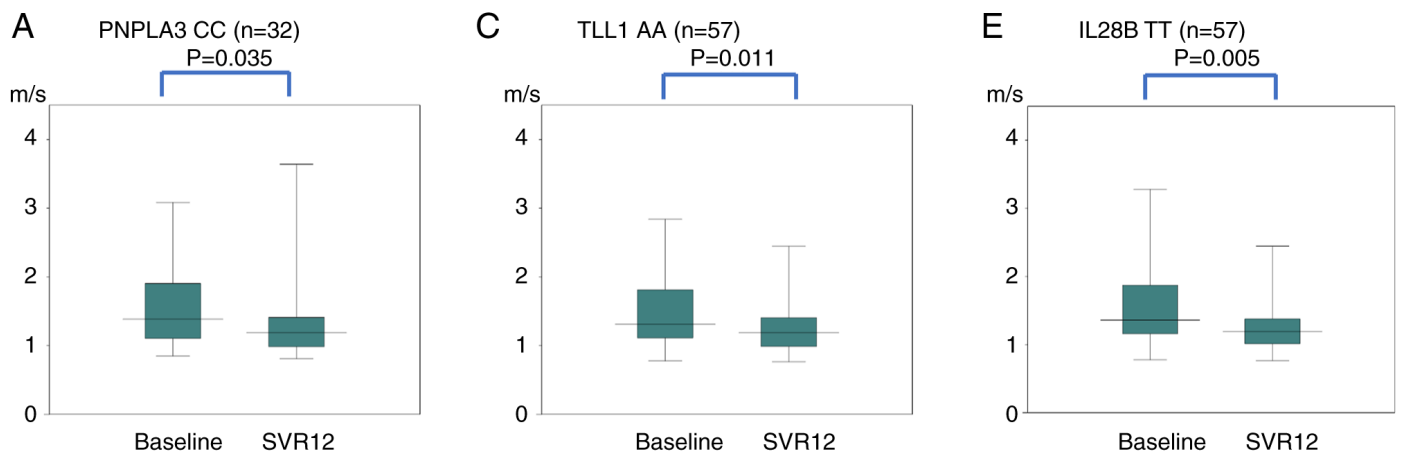

B PNPLA3 CG/GG $(n=45)$
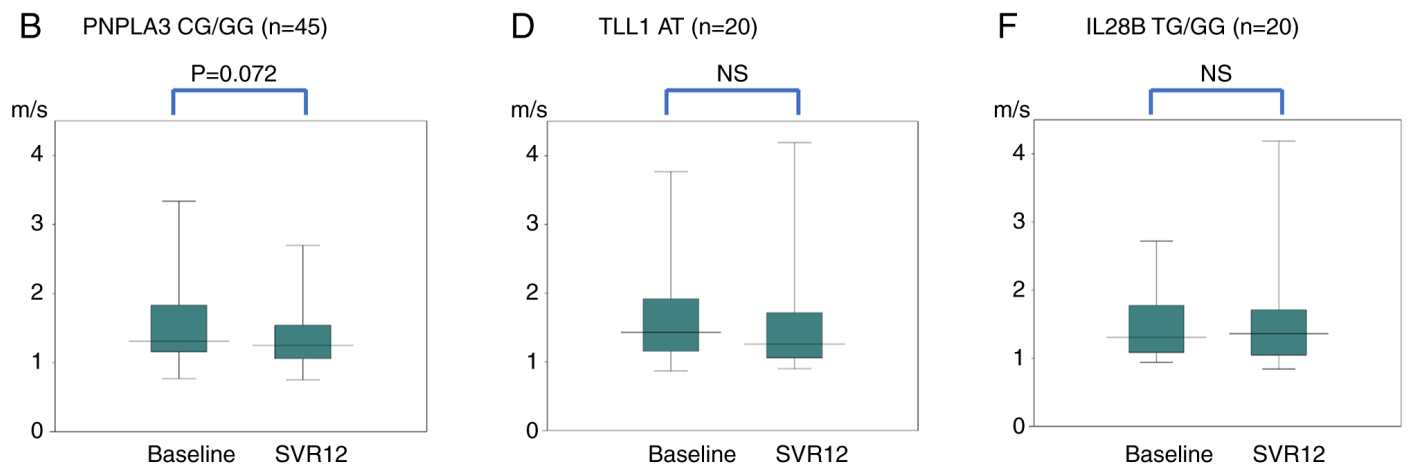

Figure 2. Changes in LS (VTTQ) for each SNP in PNPLA3: (A) CC, (B) CG/GG, TLL1; (C) AA, (D) AT, IL28B; (E) TT and (F) TG/GG genes. In the PNPLA3 gene, the median values of $\mathrm{CC}$ decreased significantly $(\mathrm{P}=0.035)$ from $1.39 \mathrm{~m} / \mathrm{s}$ before treatment to $1.19 \mathrm{~m} / \mathrm{s}$ at $\mathrm{SVR} 12$. The median values of CG/GG did not change significantly; 1.31 to $1.25 \mathrm{~m} / \mathrm{s}$. In the $T L L 1$ gene, the median values of AA decreased significantly ( $\mathrm{P}=0.011)$ from 1.31 to $1.19 \mathrm{~m} / \mathrm{s}$. The median values of AT did change significantly; 1.43 to $1.26 \mathrm{~m} / \mathrm{s}$. In the $I L 28 B$ gene, the median values of TT decreased significantly $(\mathrm{P}=0.005)$ from 1.36 to $1.19 \mathrm{~m} / \mathrm{s}$. The median values of TG/GG did not change significantly; 1.31 to $1.36 \mathrm{~m} / \mathrm{s}$. LS, liver stiffness; VTTQ, virtual touch tissue quantification; SNP, single-nucleotide polymorphism; SVR12, sustained virologic response, 12 weeks after the end of direct-acting antiviral treatment.
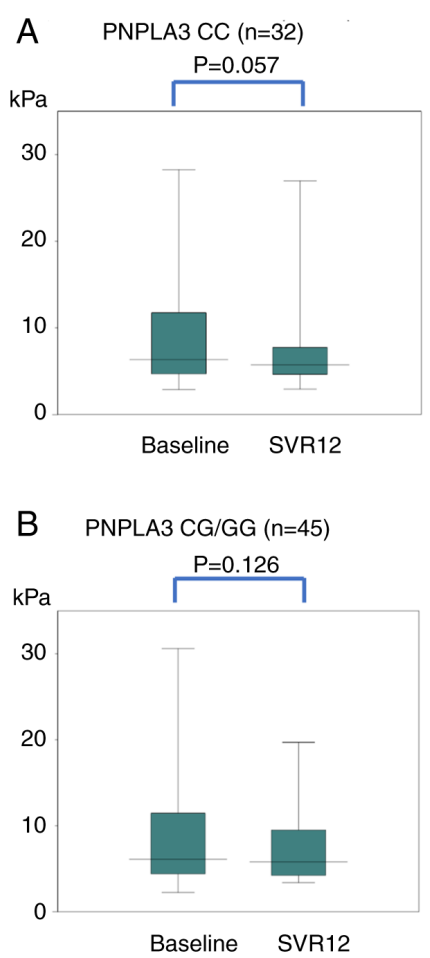
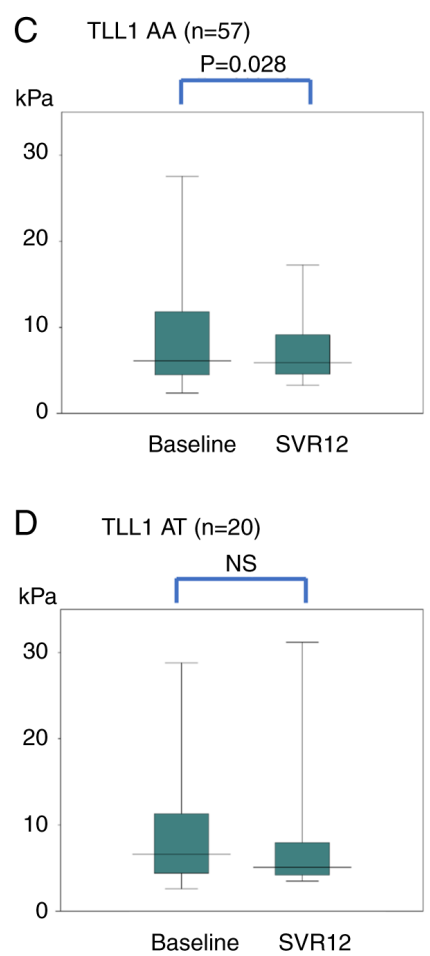
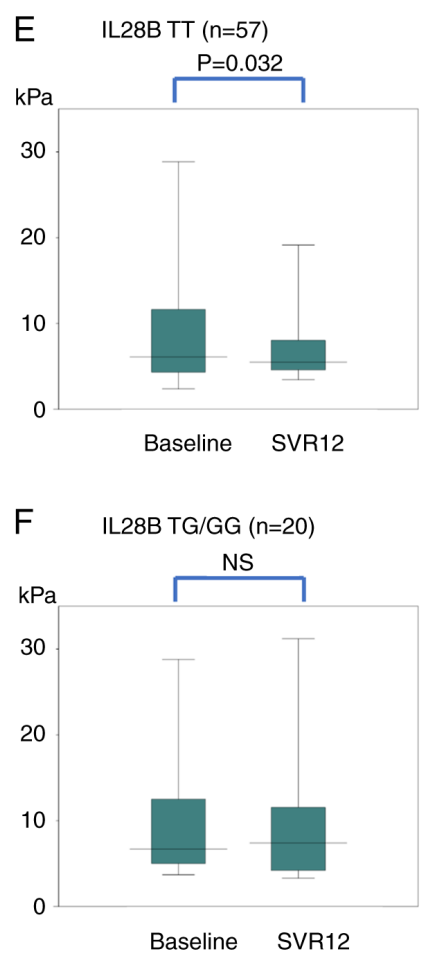

Figure 3. Changes in LS (FibroScan) for each SNP in PNPLA3: (A) CC, (B) CG/GG, TLL1; (C) AA, (D) AT, IL28B; (E) TT, and (F) TG/GG genes. In the PNPLA3 gene, the median values of CC were $6.15 \mathrm{kPa}$ before DAA treatment and $5.75 \mathrm{kPa}$ at SVR12. There was no significant difference, but there was a decreasing trend $(\mathrm{P}=0.057)$. The median values of $\mathrm{CG} / \mathrm{GG}$ did not change significantly; 6.10 to $5.80 \mathrm{kPa}$. In the $T L L 1$ gene, the median values of AA decreased significantly ( $\mathrm{P}=0.028)$ from 6.10 to $5.75 \mathrm{kPa}$. The median values of AT did change not significantly; 6.60 to $5.10 \mathrm{kPa}$. In the $I L 28 B$ gene, the median values of TT decreased significantly ( $\mathrm{P}=0.032$ ) from 6.10 to $5.50 \mathrm{kPa}$. The median values of TG/GG did not change significantly; 6.70 to $7.40 \mathrm{kPa}$. LS, liver stiffness; VTTQ, virtual touch tissue quantification; SNP, single-nucleotide polymorphism; SVR12, sustained virologic response, 12 weeks after the end of direct-acting antiviral treatment. 

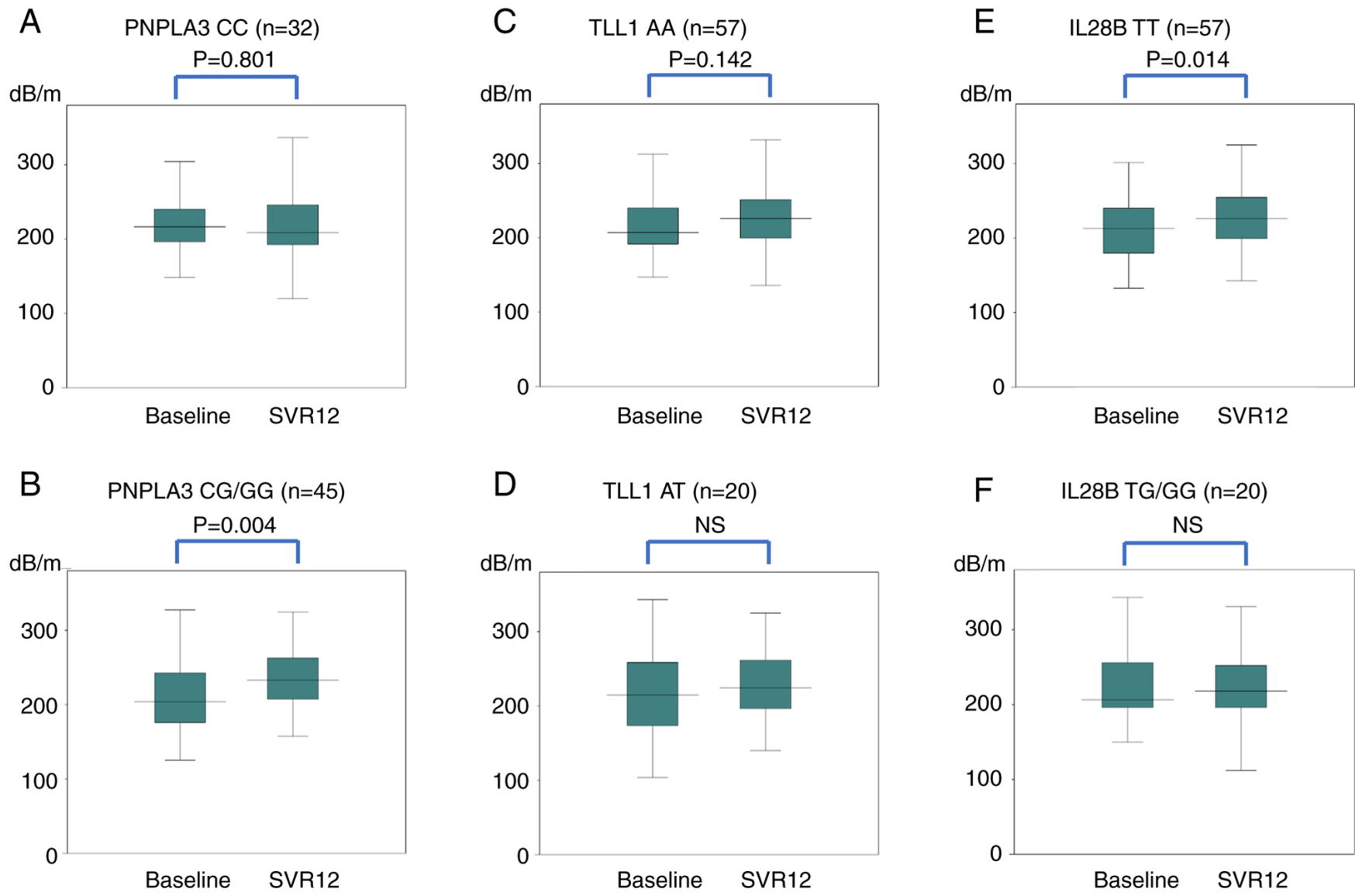

Figure 4. Changes in CAP for each SNP in PNPLA3: (A) CC, (B) CG/GG, TLL1; (C) AA, (D) AT, IL28B; (E) TT and (F) TG/GG genes. In the PNPLA3 gene, the median values of CC did not change significantly; $217 \mathrm{~dB} / \mathrm{m}$ before treatment and $209 \mathrm{~dB} / \mathrm{m}$ at SVR12. The median values of CG/GG increased significantly ( $\mathrm{P}=0.004$ ) from 204 to $233 \mathrm{~dB} / \mathrm{m}$. In the $T L L 1$ gene, the median values of AA did not change significantly; 207/m to 226 dB/m. The median values of AT did not change significantly; 215 to $225 \mathrm{~dB} / \mathrm{m}$. In the $I L 28 B$, the median values of TT increased significantly (P=0.014) from 213 to $226 \mathrm{~dB} / \mathrm{m}$. The median values of TG/GG did not change significantly; 206 to $218 \mathrm{~dB} / \mathrm{m}$. CAP, controlled attenuation parameter; SNP, single-nucleotide polymorphism; SVR12, sustained virologic response, 12 weeks after the end of direct-acting antiviral treatment.

patients, although no significant difference was observed. After treatment, LS (VTTQ) increased in 26 out of 77 cases, and LS (FibroScan) increased in 29 out of 77 cases. Of the 20 cases of IL28B TG/GG, 7 cases exhibited an increase in LS (VTTQ) and 8 cases exhibited an increase in LS (FibroScan). Further analysis is difficult due to the small number of cases, and it is necessary to investigate whether IL28B TG/GG exacerbates fibrosis after DAA treatment using a larger cohort. The median decrease in CAP for PNPLA3 CC showed a similar result; therefore, this should be investigated using a larger cohort further.

In PNPLA3 CC, the value of LS (VTTQ) decreased significantly after treatment, but there was no significant difference in LS (FibroScan). However, the post-treatment value of LS (FibroScan) apparently showed a downward trend, and therefore, it is necessary to investigate whether this trend may be significant with a larger cohort.

In addition, as LS levels are affected by inflammation, it may be useful to compare the parameters immediately after treatment and 3 months after treatment. However, it was difficult to compare these because the protocol of this survey did not include the measurement of the LS value immediately after the treatment. In future studies, the parameters should be measured immediately after treatment as well.
The present study has certain limitations. The study was conducted in a single center, and the sample size was small. To validate the results observed in this study, a larger number of samples should be investigated in the future. Additionally, this study had a short observation period; therefore, it will be necessary to consider longer observation periods in future studies. Moreover, transient elastography was performed using only the M-probe, which is intended for patients whose distance from the measurement position on the skin to the liver is $<25 \mathrm{~mm}$, suggesting a possible disadvantage in that measurement errors are more likely at distances of $\geq 25 \mathrm{~mm}$. An XL probe can be used for such patients (38).

In conclusion, the results suggested that certain SNPs were associated with the changes in liver fibrosis and steatosis after DAA treatment for $\mathrm{HCV}$ infection.

\section{Acknowledgements}

Not applicable.

\section{Funding}

No funding was received. 


\section{Availability of data and materials}

The datasets used and/or analyzed during the present study are available from the corresponding author on reasonable request.

\section{Authors' contributions}

KM was involved in data curation, formal analysis, investigation and of writing the original draft. HM was involved in conceptualization, methodology and project administration. MF, RS, MH and SM were involved in data curation and formal analysis. KN was involved in data curation and supervision. All authors have read and approved the final manuscript. KM and HM confirm the authenticity of all the raw data.

\section{Ethics approval and consent to participate}

Written informed consent was obtained from all patients. This study was approved by the Ethics Committee of Nagasaki University (Nagasaki, Japan; approval no. 15012688-3).

\section{Patient consent for publication}

Not applicable.

\section{Competing interests}

The authors declare that they have no competing interests.

\section{References}

1. Li R, Li Y, Fang X, Yang H, Wang J, Kristiansen K and Wang J: SNP detection for massively parallel whole-genome resequencing. Genome Res 19: 1124-1132, 2009.

2. Sato M, Kato N, Tateishi R, Muroyama R, Kowatari N, Li W, Goto K, Otsuka M, Shiina S, Yoshida H, et al: Impact of PNPLA3 polymorphisms on the development of hepatocellular carcinoma in patients with chronic hepatitis $\mathrm{C}$ virus infection. Hepatol Res 44: E137-E144, 2014.

3. Yasui K, Kawaguchi T, Shima T, Mitsuyoshi H, Seki K, Sendo R, Mizuno M, Itoh Y, Matsuda F and Okanoue T: Effect of PNPLA3 rs738409 variant (I148 M) on hepatic steatosis, necroinflammation, and fibrosis in Japanese patients with chronic hepatitis C. J Gastroenterol 50: 887-893, 2015.

4. Crisan D, Grigorescu M, Crisan N, Craciun R, Lupsor M, Radu C, Grigorescu MD, Suciu A, Epure F, Avram L and Leach N: Association between PNPLA3[G]/I148M variant, steatosis and fibrosis stage in hepatitis C virus-genetic matters. J Physiol Pharmacol 70, 2019

5. Matsuura K, Sawai H, Ikeo K, Ogawa S, Iio E, Isogawa M, Shimada N, Komori A, Toyoda H, Kumada T, et al: Genome-wide association study identifies TLL1 variant associated with development of hepatocellular carcinoma after eradication of hepatitis C virus infection. Gastroenterology 152: 1383-1394, 2017.

6. Huang CF, Yeh ML, Huang CI, Lin ZY, Chen SC, Huang JF, Dai CY, Chuang WL, Chen JJ and Yu ML: Tolloid-like 1 genetic variants determine fibrosis regression in chronic hepatitis $\mathrm{C}$ patients with curative antivirals. Sci Rep 8: 15058, 2018.

7. Iio E, Matsuura K, Shimada N, Atsukawa M, Itokawa N, Abe H, Kato K, Takaguchi K, Senoh T, Eguchi Y, et al: TLL1 variant associated with development of hepatocellular carcinoma after eradication of hepatitis $\mathrm{C}$ virus by interferon-free therapy. J Gastroenterol 54: 339-346, 2019.

8. Abe H, Ochi H, Maekawa T, Hayes CN, Tsuge M, Miki D, Mitsui F, Hiraga N, Imamura M, Takahashi S, et al: Common variation of IL28 affects gamma-GTP levels and inflammation of the liver in chronically infected hepatitis $\mathrm{C}$ virus patients. J Hepatol 53: 439-443, 2010.
9. Bochud PY, Bibert S, Negro F, Haagmans B, Soulier A, Ferrari C Missale G, Zeuzem S, Pawlotsky JM, Schalm S, et al: IL28B polymorphisms predict reduction of HCV RNA from the first day of therapy in chronic hepatitis C. J Hepatol 55: 980-988, 2011.

10. Kurosaki M, Tanaka Y, Nishida N, Sakamoto N, Enomoto N, Honda M, Sugiyama M, Matsuura K, Sugauchi F, Asahina Y, et al: Pre-treatment prediction of response to pegylated-interferon plus ribavirin for chronic hepatitis $\mathrm{C}$ using genetic polymorphism in IL28B and viral factors. J Hepatol 54: 439-448, 2011.

11. Ohnishi M, Tsuge M, Kohno T, Zhang Y, Abe H, Hyogo H, Kimura Y, Miki D, Hiraga N, Imamura M, et al: IL28B polymorphism is associated with fatty change in the liver of chronic hepatitis C patients. J Gastroenterol 47: 834-844, 2012.

12. Asahina Y, Tsuchiya K, Nishimura T, Muraoka M, Suzuki Y, Tamaki N, Yasui Y, Hosokawa T, Ueda K, Nakanishi H, et al: Genetic variation near interleukin 28B and the risk of hepatocellular carcinoma in patients with chronic hepatitis C. J Gastroenterol 49: 1152-1162, 2014

13. Sato M, Kondo M, Tateishi R, Fujiwara N, Kato N, Yoshida H, Taguri M and Koike K: Impact of IL28B genetic variation on HCV-induced liver fibrosis, inflammation, and steatosis: A meta-analysis. PLoS One 9: e91822, 2014.

14. Tamaki N, Kurosaki M, Higuchi M, Takada H, Nakakuki N, Yasui Y, Suzuki S, Tsuchiya K, Nakanishi H, Itakura J, et al: Genetic polymorphisms of IL28B and PNPLA3 are predictive for $\mathrm{HCV}$ related rapid fibrosis progression and identify patients who require urgent antiviral treatment with new regimens. PLoS One 10: e0137351, 2015.

15. Myers RP, Fong A and Shaheen AA: Utilization rates, complications and costs of percutaneous liver biopsy: A population-based study including 4275 biopsies. Liver Int 28: 705-712, 2008.

16. Sasso M, Beaugrand M, de Ledinghen V, Douvin C, Marcellin P, Poupon R, Sandrin L and Miette V: Controlled attenuation parameter (CAP): A novel VCTE ${ }^{\mathrm{TM}}$ guided ultrasonic attenuation measurement for the evaluation of hepatic steatosis: Preliminary study and validation in a cohort of patients with chronic liver disease from various causes. Ultrasound Med Biol 36: 1825-1835, 2010.

17. Petruzziello A, Marigliano S, Loquercio G, Cozzolino A and Cacciapuoti C: Global epidemiology of hepatitis C virus infection: An up-date of the distribution and circulation of hepatitis $\mathrm{C}$ virus genotypes. World J Gastroenterol 22: 7824-7840, 2016.

18. Attar BM and Van Thiel DH: Hepatitis C virus: A time for decisions. Who should be treated and when? World J Gastrointest Pharmacol Ther 7: 33-40, 2016.

19. Leroy V, Angus P, Bronowicki JP, Dore GJ, Hezode C, Pianko S, Pol S, Stuart K, Tse E, McPhee F, et al: Daclatasvir, sofosbuvir, and ribavirin for hepatitis $C$ virus genotype 3 and advanced liver disease: A randomized phase III study (ALLY-3+). Hepatology 63: 1430-1441, 2016.

20. Ogasawara N, Kobayashi M, Akuta N, Kominami Y, Fujiyama S, Kawamura Y, Sezaki H, Hosaka T, Suzuki F, Saitoh S, et al: Serial changes in liver stiffness and controlled attenuation parameter following direct-acting antiviral therapy against hepatitis $\mathrm{C}$ virus genotype 1b. J Med Virol 90: 313-319, 2018.

21. World Medical Association: World medical association declaration of Helsinki: Ethical principles for medical research involving human subjects. JAMA 310: 2191-2194, 2013.

22. Bamber J, Cosgrove D, Dietrich CF, Fromageau J, Bojunga J, Calliada F, Cantisani V, Correas JM, D'Onofrio M, Drakonaki EE, et al: EFSUMB guidelines and recommendations on the clinical use of ultrasound elastography. Part 1: Basic principles and technology. Ultraschall Med 34: 169-184, 2013.

23. Boursier J, Zarski JP, de Ledinghen V, Rousselet MC, Sturm N, Lebail B, Fouchard-Hubert I, Gallois Y, Oberti F, Bertrais S, et al: Determination of reliability criteria for liver stiffness evaluation by transient elastography. Hepatology 57: 1182-1191, 2013.

24. Kumagai E, Korenaga K, Korenaga M, Imamura M, Ueyama M, Aoki Y, Sugiyama M, Murata K, Masaki N, Kanto T, et al: Appropriate use of virtual touch quantification and FibroScan $\mathrm{M}$ and XL probes according to the skin capsular distance. J Gastroenterol 51: 496-505, 2016.

25. De la Vega FM, Lazaruk KD, Rhodes MD and Wenz MH: Assessment of two flexible and compatible SNP genotyping platforms: TaqMan SNP genotyping assays and the SNPlex genotyping system. Mutat Res 573: 111-135, 2005.

26. Romeo S, Kozlitina J, Xing C, Pertsemlidis A, Cox D, Pennacchio LA, Boerwinkle E, Cohen JC and Hobbs HH: Genetic variation in PNPLA3 confers susceptibility to nonalcoholic fatty liver disease. Nat Genet 40: 1461-1465, 2008. 
27. Seko Y, Sumida Y, Tanaka S, Mori K, Taketani H, Ishiba H, Hara T, Okajima A, Umemura A, Nishikawa T, et al: Development of hepatocellular carcinoma in Japanese patients with biopsy-proven non-alcoholic fatty liver disease: Association between PNPLA3 genotype and hepatocarcinogenesis/fibrosis progression. Hepatol Res 47: 1083-1092, 2017.

28. Tanaka Y, Nishida N, Sugiyama M, Kurosaki M, Matsuura K, Sakamoto N, Nakagawa M, Korenaga M, Hino K, Hige S, et al: Genome-wide association of IL28B with response to pegylated interferon-alpha and ribavirin therapy for chronic hepatitis $\mathrm{C}$. Nat Genet 41: 1105-1109, 2009.

29. Morgan TR, Ghany MG, Kim HY, Snow KK, Shiffman ML, De Santo JL, Lee WM, Di Bisceglie AM, Bonkovsky HL, Dienstag JL, et al: Outcome of sustained virological responders with histologically advanced chronic hepatitis C. Hepatology 52: 833-844, 2010.

30. Kanwal F, Kramer J, Asch SM, Chayanupatkul M, Cao Y and El-Serag HB: Risk of hepatocellular cancer in HCV patients treated with direct-acting antiviral agents. Gastroenterology 153 : 996-1005.e1, 2017.

31. Ogata F, Kobayashi M, Akuta N, Osawa M, Fujiyama S, Kawamura Y, Sezaki H, Hosaka T, Kobayashi M, Saitoh S, et al: Outcome of all-oral direct-acting antiviral regimens on the rate of development of hepatocellular carcinoma in patients with hepatitis $\mathrm{C}$ virus genotype 1-related chronic liver disease. Oncology 93: 92-98, 2017.

32. Makiyama A, Itoh Y, Kasahara A, Imai Y, Kawata S, Yoshioka K, Tsubouchi H, Kiyosawa K, Kakumu S, Okita K, et al: Characteristics of patients with chronic hepatitis $\mathrm{C}$ who develop hepatocellular carcinoma after a sustained response to interferon therapy. Cancer 101: 1616-1622, 2004.

33. Asahina Y, Tsuchiya K, Nishimura T, Muraoka M, Suzuki Y, Tamaki N, Yasui Y, Hosokawa T, Ueda K, Nakanishi H, et al: $\alpha$-Fetoprotein levels after interferon therapy and risk of hepatocarcinogenesis in chronic hepatitis C. Hepatology 58: 1253-1262, 2013
34. El-Serag HB, Kanwal F, Richardson P and Kramer J: Risk of hepatocellular carcinoma after sustained virological response in Veterans with hepatitis $\mathrm{C}$ virus infection. Hepatology 64: 130-137, 2016.

35. Ioannou GN, Green PK, Beste LA, Mun EJ, Kerr KF and Berry K Development of models estimating the risk of hepatocellular carcinoma after antiviral treatment for hepatitis C. J Hepatol 69: 1088-1098, 2018.

36. Motoyama H, Tamori A, Kubo S, Uchida-Kobayashi S, Takemura S, Tanaka S, Ohfuji S, Teranishi Y, Kozuka R, Kawamura E, et al: Stagnation of histopathological improvement is a predictor of hepatocellular carcinoma development after hepatitis C virus eradication. PLoS One 13: e0194163, 2018.

37. Tanaka A, Uegaki S, Kurihara H, Aida K, Mikami M, Nagashima I, Shiga J and Takikawa H: Hepatic steatosis as a possible risk factor for the development of hepatocellular carcinoma after eradication of hepatitis $\mathrm{C}$ virus with antiviral therapy in patients with chronic hepatitis C. World J Gastroenterol 13: 5180-5187, 2007.

38. Myers RP, Pomier-Layrargues G, Kirsch R, Pollett A, Duarte-Rojo A, Wong D, Beaton M, Levstik M, Crotty P and Elkashab M: Feasibility and diagnostic performance of the FibroScan XL probe for liver stiffness measurement in overweight and obese patients. Hepatology 55: 199-208, 2012.

This work is licensed under a Creative Commons Attribution-NonCommercial-NoDerivatives 4.0 International (CC BY-NC-ND 4.0) License. 